\title{
New Approaches to Sample Preparation and Integrated Spectroscopic Methods for the Identification of Polioxyethylene Triolate Sorbitane for Pharmaceutical Examination of Drugs
}

\author{
Yerbolat Orazbekuly ${ }^{1,2}$, Gulzat Aitkaliyeva ${ }^{1}$, Madeniyet Yelubay ${ }^{3}$
}

1. National Center for expertise of medicines and medical devices of the Ministry of Healthcare of the Republic of Kazakhstan, Satbayev University, Almaty, 050013, Kazakhstan

2. National Center for expertise of medicines and medical devices of the Ministry of Healthcare of the Republic of Kazakhstan (NCEM)

3. S.Toraigyrov Pavlodar State University, Pavlodar, 140008, Kazakhstan

\begin{tabular}{|c|c|}
\hline Info Article & ABSTRACT \\
\hline Submitted: $07-06-2020$ & Due to the fast pace of development of spectroscopic research \\
\hline Revised: 01-07-2020 & methods in the pharmaceutical expertise of drugs presented in the United \\
\hline Accepted: 01-09-2020 & States Pharmacopeia (USP) and European Pharmacopoeia (Ph. Eur.), in this \\
\hline *Corresponding author & paper, we examined complex methods for the identification and preparation \\
\hline Yerbolat Orazbekuly & $\begin{array}{l}\text { for analysis of polyethylene sorbitan trioleate. Two new systems were } \\
\text { identified for purification of } 98 \% \text { polyoxyethylene sorbitan trioleate from }\end{array}$ \\
\hline & organic impurities in column chromatography: acetonitrile $100 \%$ and \\
\hline bolashik@mail.ru & acetonitrile/acetone $7.5 / 2.5$. It was also revealed that a chamber with \\
\hline & $\begin{array}{l}\text { metallic lodine was the most suitable for selecting an eluent and controlling } \\
\text { the cleaning by the TLC method. Proton NMR did not detect organic }\end{array}$ \\
\hline & impurities. Identification of polyoxyethylene sorbitan trioleate was carried \\
\hline & $\begin{array}{l}\text { out on } \mathrm{H} 1, \mathrm{C} 13, \mathrm{COSY} \text { and IR spectra. These research methods are } \\
\text { characterized by simplicity in sample preparation, the availability of }\end{array}$ \\
\hline & $\begin{array}{l}\text { reagents, the effectiveness of identification and quantification analyzes, and } \\
\text { the efficiency in labor and material costs. }\end{array}$ \\
\hline & $\begin{array}{l}\text { Keywords: TWEEN-85, NMR, FTIR, Column Chromatography, sample } \\
\text { preparation, pharmacopeia }\end{array}$ \\
\hline
\end{tabular}

\section{INTRODUCTION}

Modern spectroscopy methods are increasingly used in the examination of pharmaceuticals (Holzgrabe, 2010). The FDA regards NMR and MS spectroscopy methods as the next generation USP (FDA and US Pharmacopeia, 2012). Proof of the development of spectroscopic methods in the examination of drugs can be attributed to a collection of works and a number of pharmacopeia methods of identification and analysis in the European pharmaceutical corporation (Holzgrabe, et al., 2008; European Pharmacopoeia, 2019). Also, the International Council for the Harmonization of Technical Requirements for the Registration of Medicines for Medical Use (ICH) by the working group of international experts "Development of analytical procedures Q14 and revision of the analytical validation procedure Q2 (R1)", where NCEM is one of the members, considers the decision to include NIR, NMR, CE-MS, CE-ICP-MS, LC-NMR, GC-MS, LCMS in this manual (ICH Quality guidelines, 2018).

In this paper, we examined the new complex methods of sample preparation for analysis and identification of polyethylene sorbitan trioleate (TWEEN-85), which is used in various industries, such as the food industry, pharmaceuticals, medicine, biotechnology, chemical industry, oil industry, etc. (Ema, et al 2008- Pandemic H1N1, 2009). The production of polyoxyethylene sorbitans in the world is constantly increasing. In Europe and America, people eat about $100 \mathrm{mg}$ per day of polyoxyethylene sorbitan as a food supplement (Ema, et al 2008). Flu vaccines contain $25 \mathrm{mcg}$ of polysorbate 80 per dose (Pandemic H1N1, 2009). Polyoxyethylene sorbitans are nonionic surface active substances (nonionic surfactants), which by their nature are emulsifiers. 
Nonionic surfactants weaken the surface tension at the separation of two phases - oil and water (Abramzon, 1979). There are several types of polysorbates: monolaurate is indicated by the number 20 (TWEEN -20), monopalmitate -40 (TWEEN-40), monostearate -60 (TWEEN -60), monooleate -80 (TWEEN -80) and trioleate (TWEEN -85). Polysorbates are of natural origin because they are based on sorbitol (in other words, sorbitol, glucite is a substance with a sweet taste and often used as a substitute for sugar in dietary products, it is obtained from fruits, often from fruit seeds) and fatty acids from basic oils: coconut TWEEN -20, palm - TWEEN -40 and -60, olive TWEEN -80 and 85.

In the countries of the European Union and in the USA, for the identification and quantification of polyoxyethylene sorbitan trioleate, mainly chromatographic methods are used, as well as the method of infrared absorption spectroscopy (European Pharmacopoeia, 2019; - United States Pharmacopeia, 2019), which include sample preparation, use and the constant presence of a high-quality reference standard (USP , EDQM) for each analysis of the drug and the shelf life of which often does not exceed 2 years.

The Republic of Kazakhstan, like other CIS countries, is a developing country. In our country, constant work is underway to harmonize the Kazakhstan Pharmacopoeia with the European Pharmacopoeia, which requires a lot of time, and therefore the Kazakhstan Pharmacopoeia is updated very lateFor the Republic of Kazakhstan, as well as other CIS countries, most of the reagents and reference standards are costly and often difficult to access due to frequent interruptions in the logistics of the necessary reagents from the countries of the European Union and the USA, which affects the quality and completeness of the examination of the drug entering the market, which is very relevant during the COVID-19 pandemic.

The presented new complex method of sample preparation is better than the previous ones in that it uses available chemicals, and the identification of polyoxyethylene sorbitan trioleate after the new method of sample preparation with the NMR spectrometer is characterized by the speed of analysis and low analysis costs. To confirm the validity of the assignment of NMR spectra, we also conducted studies on an FTIR spectrometer.

\section{MATERIALS AND METHODS}

The object of study is Tween-85 (polyoxyethylene sorbitan trioleate) (Figure 1) (li, et al 2009). The studies were conducted in the laboratory of Saint Louis University (USA). The study involved techniques such as thin-layer chromatography (TLC), column chromatography, IR spectrometry, and NMR. Column chromategraphy on alumina 60 was used to obtain pure Tween-85 for NMR and IR spectrometry studies. The solvent for the reaction product was selected by thin-layer chromatography. Solvents were distilled off by a vacuum pump with a trap of liquid nitrogen. Aldrich calibrated column with a $100 \mathrm{~mL}$ solvent tank was used for column chromatography. Column chromatography samples were taken in $5 \mathrm{~mL}$ tubes. Each tube was checked for impurities by thin layer chromatography on a silica plate with a pre-selected solvent. The bands on a pre-dried plate were observed under standard conditions in a TLC viewing chamber. 30 min before analysis, a beaker with $2 \mathrm{~g}$ of metallic iodine was placed in a TLC viewing camera equipped with $15 \mathrm{~W} 254 \mathrm{~nm}$ and $15 \mathrm{~W} 365 \mathrm{~nm}$ ultraviolet tubes to saturate it with iodine vapor.

NMR studies were performed on a Bruker AVANCE 3-400 spectrometer in $5 \mathrm{~mm}$ Series 400 Thrift NMR tubes 0.01475 in wall thickness from Aldrich with deuterated dimethyl sulfoxide. To confirm the assignment of the NMR peaks, the IR spectra of polyoxyethylene sorbitan trioleate were recorded on a Shimadzu FTIR-8400S spectrometer on a PIKE Miracle nozzle with a ZnSe crystal. The spectrum of the desired sample is obtained by the ratio of scanning with the sample to scanning without a sample on the surface of the crystal. To prepare the crystal for analysis, it should be cleaned with a suitable mild solvent such as isopropyl alcohol. The sample must be in close contact with the crystal to obtain the FTIR spectrum. To obtain a spectrum, a drop of sample was placed on a crystal and data was collected.

For reliability of the result, the IR spectra of polyoxyethylene sorbitan trioleate were re-taken on a tablet from $\mathrm{KBr}$. To prepare the test sample, a method of mixing a sample of $5 \%$ by weight with $\mathrm{KBr}$ and then compressing the tablet was used. Grinding and mixing was carried out using a mortar and pestle. A $0.5 \mathrm{~mm}$ thick tablet obtained by compressing the prepared mixture with a hydraulic press was placed in a transmission holder for further scanning. 


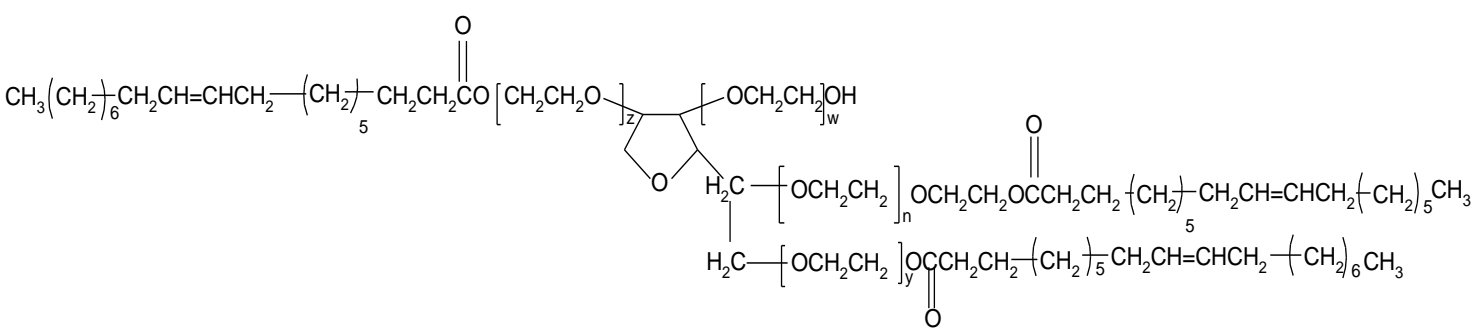

Figure 1. Molecular structure Tween-85 where $n+w+y+z=19$, some physical properties of Tween-85 are (Table I).

Table I. Key indicators of Tween-85

\begin{tabular}{cc}
\hline Indicators & Specifications \\
\hline Density, g/ $\mathrm{cm}^{3}$ & 1,028 \\
Refractive index & $1.47-1.472$ \\
Flash point, ${ }^{\circ} \mathrm{F}$ & $>230$ \\
Viscosity, mPA & $250-450$ \\
The content of the main & more $98 \%$ \\
substance & no more $2 \%$ \\
The content of organic impurities & \\
\hline
\end{tabular}

\section{RESULTS AND DISCUSSION}

For thin-layer chromatography, a silicon oxide plate was used. According to literary sources, it was found that for TLC, the acetone-water system from $8 / 2$ to $5 / 5$ is suitable. The authors propose to observe polyoxyethylene sorbitans on TLC in a chamber with metallic iodine (Iodine) or by spraying with $50 \%$ sulfuric acid (Katic et al., 1998). However, a system proposed from literature for TLC on a silica wafer did not perform well in alumina column chromatography. We also note that the method of spraying with $50 \%$ sulfuric acid to observe polyoxyethylen sorbitan also did not give the proper results (Katic et al., 1998).

Further, for Tween-85, we found 2 systems: acetonitrile $100 \%$ and the acetonitrile-acetone 7.5/2.5 system. The systems for studying the obtained products on TLC behaved equally efficiently, both on a silicon oxide plate and on alumina column chromatography. To select an eluent and control the purification by the TLC method, a chamber with metallic iodine was used. For further purification of Tween-85 from impurities, an acetonitrile-acetone 7.5/2.5 system that we found was chosen for column chromatography from aluminum oxide. The acetonitrile-acetone 7.5/2.5 system, unlike the $100 \%$ acetonitrile system, requires less time for cleaning.

Solvent stripping was carried out by a vacuum pump with a liquid nitrogen trap. Acetone was distilled off at room temperature (bp $\left.56.1^{\circ} \mathrm{C}\right)$, and acetonitrile was distilled off by raising the temperature to $50^{\circ} \mathrm{C}\left(\mathrm{bp} 82^{\circ} \mathrm{C}\right)$.

For investigation on an AVANCE 3-400 Bruker NMR spectrometer, 20\% Tween-85 reaction solutions in deuterated dimethyl sulfoxide were taken and proton spectra $\left({ }^{1} \mathrm{H}\right)$, carbon spectra $\left.{ }^{13} \mathrm{C}\right)$ and two-dimensional COSY spectra were taken (Figure 2 and Figure 3).

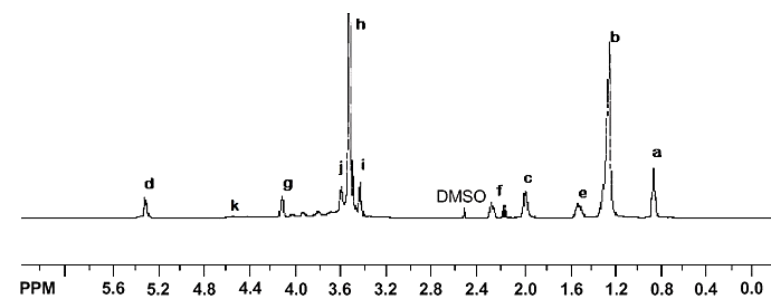

Figure 2. Proton NMR spectrum of Tween-85

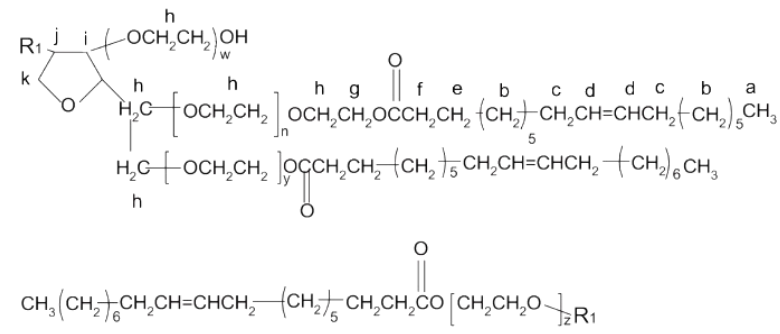

Figure 3. Corresponding of proton spectrum of Tween-85 in formula, where $n+w+y+z=19$ 
Table II. Chemical shifts of bond groups Tween-85

\begin{tabular}{cc}
\hline Chemical shift & Values \\
\hline$\delta \mathrm{a}$ & $0.85 \mathrm{ppm}$ \\
$\Delta \mathrm{b}$ & $1.2 \mathrm{ppm}$ \\
$\Delta \mathrm{c}$ & $2.0 \mathrm{ppm}$ \\
$\Delta \mathrm{d}$ & $5.3 \mathrm{ppm}$ \\
$\Delta \mathrm{e}$ & $1.5 \mathrm{ppm}$ \\
$\Delta \mathrm{f}$ & $2.3 \mathrm{ppm}$ \\
$\Delta \mathrm{g}$ & $4.15 \mathrm{ppm}$ \\
$\Delta \mathrm{h}$ & $3.5 \mathrm{ppm}$ \\
$\Delta \mathrm{i}$ & $3.4 \mathrm{ppm}$ \\
$\Delta \mathrm{j}$ & $3.6 \mathrm{ppm}$ \\
$\Delta \mathrm{k}$ & $4.5 \mathrm{ppm}$ \\
\hline
\end{tabular}

${ }^{1} \mathrm{H}$ NMR spectrum shows large peak (h) at $\delta=3.5 \mathrm{ppm}$ belonging to two methylene protons in $(\mathrm{OCH} 2 \mathrm{CH} 2-) \mathrm{n}$ groups and peak (b) at $\delta=1.2 \mathrm{ppm}$ belonging to two methylene protons in $\mathrm{CH} 2$ groups. The data on the assignment of the spectra are confirmed by the authors (Huimeng et al., 2008; Gordon et al., 1976). As can be seen from the proton spectrum of impurities after sample preparation is not observed, which confirms the effectiveness of the selected methods for sample preparation. To confirm the assignments of proton signals in the ${ }^{1} \mathrm{H}$ NMR spectrum of Tween-85, studies were conducted on COSY and ${ }^{13} \mathrm{C}$.

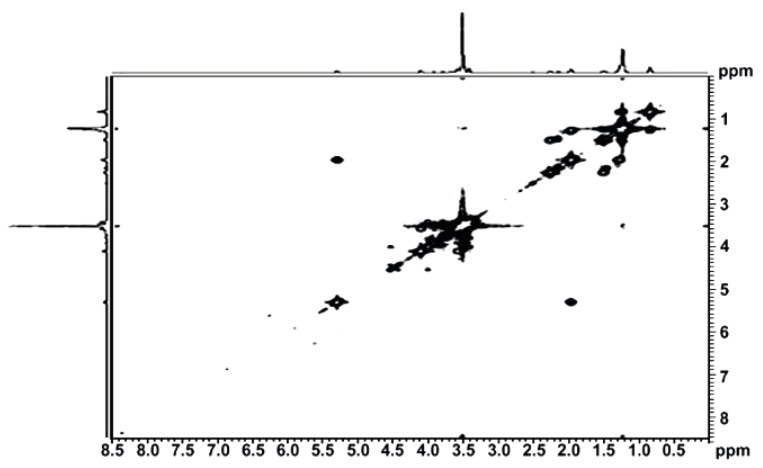

Figure 4. COSY Tween-85

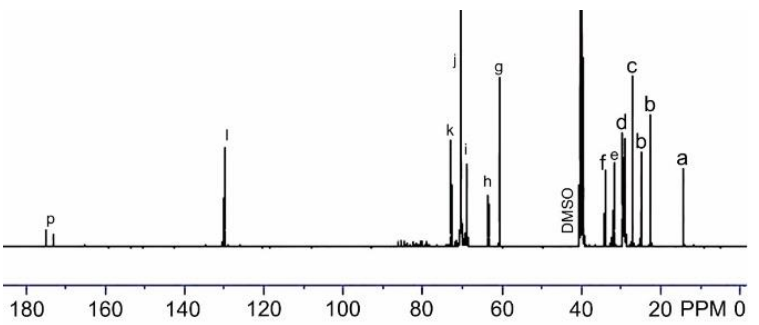

Figure 5. Carbon spectrum of Tween-85
Having analyzed all the cross-peaks of the COSY Tween-85 spectrum, it was found that the peak in the $3.5 \mathrm{ppm}$ region related to $\left(\mathrm{OCH}_{2} \mathrm{CH}_{2}-\right) \mathrm{n}$ overlaps the quartet and triplet peaks in $\mathrm{R}_{1}-\mathrm{CH}_{2}\left(\mathrm{R}_{2}\right)-\mathrm{CH}_{2} \mathrm{R}_{3}$, where $\mathrm{R}_{1}$ is an oxygencontaining heterocyclic ring, $R_{2}$ and $R_{3}$ is polyoxyethylene oleate. The peak (p) at $177 \mathrm{ppm}$ corresponds to $\mathrm{C}=0$ bonds in the ether groups. The band (l) in the region of 130 ppm belongs to $-\mathrm{C}=\mathrm{C}-$ located in alkenes. The four peaks at 62ppm, 68 ppm, 70ppm and 74ppm correspond to 4 different CO bonds of ether groups. The first peak $(\mathrm{k})$ in the $74 \mathrm{ppm}$ region is connected by $\mathrm{CO}$ attached to an oxygen-containing heterocyclic ring. The second large band ( $\mathrm{j}$ ) in the region of $70 \mathrm{ppm}$ belongs to the $\mathrm{CO}$ bonds of the ether group in $\left(-\mathrm{CH}_{2}-\mathrm{CH}_{2}-\mathrm{O}-\mathrm{CH}_{2}-\right.$ $\mathrm{CH}_{2}-\mathrm{O}-\mathrm{)}$. The third peak (i) in the region of $68 \mathrm{ppm}$ belongs to the $\mathrm{CO}$ bonds in the $-\mathrm{CO}(\mathrm{O}) \mathrm{C}-$. The carbon-oxygen bond band (h) located in the oxygen-containing heterocyclic compound is in the region of $62 \mathrm{ppm}$.

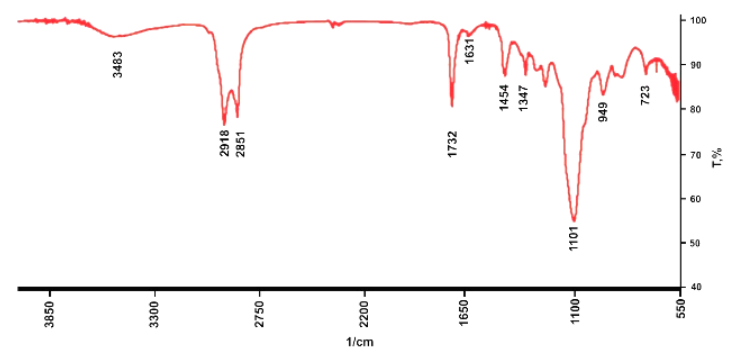

Figure 6. IR spectrum Tween-85

The band (g) at 60ppm refers to $\mathrm{R}-\mathrm{CH}_{2}-\mathrm{OH}$ bonds. Deuterated dimethyl sulfoxide is located in the region of $39.5 \mathrm{ppm}$. The peak (f) in the $35 \mathrm{ppm}$ region refers to $-\mathrm{CH}-$ in the $\mathrm{R}_{1}-\mathrm{CH}\left(\mathrm{R}_{2}\right)-\mathrm{R}_{3}$ bonds in the oxygen-containing heterocyclic ring, and the band (e) in the 32ppm region refers to $-\mathrm{CH}-$ in the $\mathrm{R}_{1}-\mathrm{CH}\left(\mathrm{R}_{2}\right)-\mathrm{R}_{3}$ bonds in the branch attached to the oxygen-containing heterocyclic ring. The band $(\mathrm{d})$ at $29 \mathrm{ppm}$ refers to the $-\mathrm{C}-\mathrm{C}$ - first carbon in the group (-O- $\left.\mathrm{CH}_{2}-\mathrm{CH}_{2}-\mathrm{O}-\mathrm{CH}_{2}-\mathrm{CH}_{2}-\mathrm{O}-\right)$. The peak (c) at $26 \mathrm{ppm}$ refers to $-\mathrm{CH}_{2}-$ in the $-\mathrm{CH}_{2}-\mathrm{CH}=\mathrm{CH}-$ bonds, and the band (b) at 24ppm and 22ppm are $\left(-\mathrm{CH}_{2}-\right)$. The 16 ppm peak (a) belongs to the $-\mathrm{CH}_{3}$ group located at the end of Tween-85 tails (Gordon, 1976). IR spectra of polyoxyethylene sorbitan trioleate were recorded on an FTIR-8400S Shimadzu IR spectrometer on a PIKE Miracle nozzle with a ZnSe crystal (Figure 6). For reliable results, the IR spectra of polyoxyethylene sorbitan trioleate were re-recorded on a $\mathrm{KBr}$ tablet. 
After analyzing the literature (li et al, 2009; Karic et al., 1998; Huaimeng et al., 2008; Gordon, et al., 1976; Coates 2000), we can conclude that the bands $3483 \mathrm{~cm}^{-1}$ are associated with $\mathrm{O}-\mathrm{H}$ groups, and the bands at $1732 \mathrm{~cm}^{-1}$ to $-\mathrm{C}(0)-0$-. The bands at 2918 and $2851 \mathrm{~cm}^{-1}$ can be attributed to asymmetric and non-asymmetric aliphatic $-\mathrm{CH}_{2}$ groups, respectively. Absorption bands at 1631 and $1454 \mathrm{~cm}^{-1}$ relate to vibrations of an oxygencontaining heterocyclic ring. The $1347 \mathrm{~cm}^{-1}$ bands relate to $\mathrm{CH}$ vibrations in $-\mathrm{CH}_{3}$ and $-\mathrm{CH}_{2}$ groups. In addition, there is a large peak in the region of $1101 \mathrm{~cm}^{-1}$, which can be attributed to $\mathrm{C}-\mathrm{O}-\mathrm{C}$ asymmetric stretching vibrations in the ether bond. The bands of $949 \mathrm{~cm}^{-1}$ relate to symmetric vibrations of the $\mathrm{C}-\mathrm{O}-\mathrm{C}$ valence groups. The peak in the region of $723 \mathrm{~cm}^{-1}$ to vibrations of $\left(-\mathrm{CH}_{2}-\right) \mathrm{n}$.

\section{CONCLUSIONS}

Novel complex methods for the preparation for analysis and identification of polyethylene sorbitan trioleate was studied for the first time. New system of acetonitrile/acetone 7.5/2.5 for purification of $98 \%$ polyoxyethylene sorbitan trioleate from organic impurities in column chromatography was found. To select an eluent and control the purification by the TLC method, a chamber with metallic iodine was used. The structure of sample was studied and proven by different methods of NMR and additionally verified by FTIR spectroscopy. Proton NMR did not detect organic impurities. The advantages of this method are characterized by simplicity in sample preparation, the availability of reagents, the effectiveness of identification and quantification analyzes, and the efficiency in material costs.

\section{ACKNOWLEDGEMENTS}

This research is funded by the Science Committee of the Ministry of Education and Science of the Republic of Kazakhstan (Grant No. AP05130530).

\section{REFERENCES}

A Gordon, R. 1976, Ford Sputnik khimika. -M.:Mir, $-312 p$.

Abramzon A.A., Gayevoi G.M. 1979, Poverkhnostnoaktivnye veshestva.- L.: Chimiya, 376 p.

Ema M, Hara H, Matsumoto M, Hirata-Koizumi M, Hirose A, Kamata E. 2008, "Evaluation of developmental neurotoxicity of polysorbate 80 in rats". Reproductive Toxicology. 25 (1): 89-99.
European Pharmacopoeia. 2.2.64. Peptide identification by nuclear magnetic resonance spectrometry. Edition 10.2. p. 118.

European Pharmacopoeia. 5.16. Crystallinity. Describes various test to determine crystallinity e.g. Solid state NMR. Edition 10.2. p. 797.

European Pharmacopoeia. Haemophilus type $\mathrm{b}$ and meningococcal group C conjugate vaccine. Production section: characterization and identification of the linear copolymer polyribosylribitol phosphate. Edition 10.2. p. 979.

European Pharmacopoeia. Meningococcal group C conjugate vaccine. Production section: identification and serological specifity. Edition 10.2. p. 1010.

European Pharmacopoeia..2.2.24. Absorption spectrophotometry, infrared.

European Pharmacopoeia..2.4.22 C. Composition of fatty acids by gas chromatography.

FDA and US Pharmacopeia Explore Expanding Use of NMR for Drug Quality Testing. Spectroscopy (online journal). 2012, November 19, (http://www.spectroscopyonline.com/fdaand-us-pharmacopeia-explore expandinguse-nmr-drug-quality-testing)

Holzgrabe U., 2010. Quantitative NMR spectroscopy in pharmaceutical application, Progress in Nuclear Magnetic Resonance Spectroscopy, 57: 229-240. https://doi.org/10.1016/j.pnmrs.2010.05.0 $\underline{01}$

ICH Quality guidelines. Q2(R2)/Q14 EWG. Analytical procedure development and revision of Q2(R1) Analytical Validation.

J Coates. 2000, Interpretation of Infrared Spectra, A Practical Approach. Encyclopedia of Analytical Chemistry. R.A. Meyers (Ed.).pp. 10815-10837. Ó John Wiley \& Sons Ltd, Chichester,.

L Xiang-Hong, D Shu-Duan, F Hui, M Guan-Nan. 2009. Inhibition by tween-85 of the corrosion of cold rolled steel in $1.0 \mathrm{M}$ hydrochloric acid solution. -J Appl Electrochem 39:1125-1135

M Katic, J Frantar, I Grgic, H Podgornic, and AP Erdih. 1998. Polyoxyethylene Stimulates Lignin Peroxidase. Production in phanerochcete chrysosporium. -Folia Microbiol. 43 (6), 631-634 
Pandemic H1N1 (pH1N1) Influenza Vaccine Quick Reference Guide Winnipeg Regional Health Authority 2009

U.Holzgrabe, I.Wawer, B.Diehl. NMR spectroscopy in pharmaceutical analysis. Elsevier.2008.

United States Pharmacopeia (USP) and the National Formulary (NF) 621. General Chapter. Chromatography-System Suitability.

W Huimeng, Z Haizhen, Z Jiaqi, Y Shuo, L Chen and YCC Angewandte. 2008. Chemie
International Edition (C) Wiley-VCH 69451 Weinheim, Germany. pp.3

Y Orazbekuly, GI Boiko, NP Lubchenko, SA Dergunov. 2014. Novel high-molecular multifunctional reagent for the improvement of crude oil properties. Fuel Processing Technology. -- Vol. 128. - P. 349353. 